\title{
Analysis of risk factors and postoperative complications in patients with Crohn's disease
}

\author{
Rogério SAAD HOSSNE${ }^{1}$, Ligia Yukie SASSAKI ${ }^{2}$, Julio Pinheiro BAIMA² ${ }^{2}$ José Donizeti de MEIRA JÚNIOR ${ }^{1}$ \\ and Luana Moraes CAMPOS ${ }^{1}$
}

Received 19/2/2018

Accepted 2/5/2018

\begin{abstract}
Background - The post-operative complications rate is greater in patients with Crohn's disease than in other abdominal surgeries due to other benign conditions. Prevention and management of such complications are important factors in the care of these patients. Objective-The objectives of this research are to analyze the rate of postoperative complications and the major risk factors in patients with Crohn's disease. Methods - A descriptive and retrospective study based on analysis of medical records of patients with Crohn's disease undergoing ileal and/or colonic resection, which analyzed the main surgical complications and their major risk factors. Results - Forty-four surgical procedures and thirty-seven patients were analyzed. Most were female $(56.7 \%)$. Postoperative complications were observed in $18(40.9 \%)$ surgeries. The disease duration $(P=0.04)$, the penetrating behavior $(P=0.013)$, the time between diagnosis and the first surgery $(P=0.04)$, malnutrition with low body mass index $(\mathrm{BMI})$, duration of surgery $(P=0.016)$, and the size of the removed specimen $(P=0.014)$ were associated with higher rates of complications. The use of drugs blocking tumor necrosis factor up to eight weeks before surgery was not significantly associated with higher complications rates or increased need for reoperation. Conclusion - The complication rate observed in this study is similar to published data. The duration of the disease, the penetrating behavior, the size of the removed specimen, the duration of the surgery, and BMI are important risk factors for perioperative complications in Crohn's disease.
\end{abstract}

HEADINGS - Secondary prevention. Risk factors. Digestive system surgical procedures. Postoperative complications. Inflammatory bowel disease.

\section{INTRODUCTION}

Crohn's disease (CD) can cause transmural inflammation and can affect any segment of the digestive tract (especially terminal ileum and perianal region). It is characterized by a discontinuous involvement of the gastrointestinal tract, with affected areas interspersed with areas of normal mucosa. Unlike ulcerative colitis, $\mathrm{CD}$ is commonly associated with complications such as abscesses, fistulas and stenosis ${ }^{(1,2)}$.

The worldwide incidence of $\mathrm{CD}$ in the adult population ranges from 0.1 to 20.2 per 100,000 people per year, and its prevalence in North America is 26 to 199 cases per 100,000 inhabitants per year ${ }^{(3-5)}$. The incidence of CD in the Midwest of São Paulo state during the years of 2001 to 2005 was 3,5 cases per 100.000 people, and its prevalence was 5,65 cases per 100.000 people $^{(6)}$. Although South America is considered an area with a low frequency of CD, its incidence is rising in the countryside of both the São Paulo and Minas Gerais states in the past few decades ${ }^{(7,8)}$.

Despite the reduction in the need for surgery due to recent advances in the clinical management of $\mathrm{CD}$, it is estimated that between $70 \%$ and $90 \%$ of patients with $\mathrm{CD}$ will require surgical intervention at some point during the progression of the disease ${ }^{(9)}$.

Several authors ${ }^{(10-12)}$ have already proven that patients with inflammatory bowel diseases (IBD) are more prone to perioperative complications, due to pre-existing clinical condition, nutritional status and drug use, especially corticoids and immunomodulators. However, the rates of perioperative complications vary widely $(5 \%$ to $60 \%)^{(10-13)}$ according to the group. Some factors widely influence the rate of perioperative complications: presence of multidisciplinary team, experience of the surgeon, center of reference to treat IBD, medications in use and duration.

Regarding the medications, there is a growing concern about the safety of perioperative use of biologic anti-TNF (tumor necrosis factor) agents, as Infliximab (IFX) and Adalimumab (ADA). In a recent meta-analysis article ${ }^{(14)}$, with extensive review of the literature, the postoperative complications associated with the use of anti-TNF were evaluated. One of the few multicenter studies performed in Brazil, analyzing 76 patients with CD did not show an increased risk of complications with the use of biological therapy ${ }^{(15)}$

Thus, the objective of this study is to analyze the rate of perioperative complications and to identify their risk factors in patients with intestinal CD undergoing surgical treatment.

\section{METHODS}

\section{Ethical aspects of the survey}

This survey was approved by the Department of Surgery and Orthopedics, Botucatu Medical School, São Paulo State University - UNESP. Grant \#2014/01091-2, São Paulo Research Foundation (FAPESP). Ethics Committee approval number: 3547/2010.

A retrospective observational study was conducted through the collection of data from medical records of patients with CD submitted to abdominal surgical intervention.

Declared conflict of interest of all authors: none

Disclosure of funding: no funding received

${ }^{1}$ Universidade Estadual Paulista (UNESP), Faculdade de Medicina, Departamento de Cirurgia e Ortopedia, Botucatu, SP, Brasil. ${ }^{2}$ Universidade Estadual Paulista (UNESP), Faculdade de Medicina, Departamento de Clínica Médica, Botucatu, SP, Brasil.

Corresponding author: Rogério Saad Hossne. Orcid: 0000-0002-8166-0304. E-mail: saad@fmb.unesp.br 
All patients diagnosed with $\mathrm{CD}$ and monitored at the IBD outpatient clinic of Botucatu Medical School who underwent abdominal surgery related to CD itself in the last 10 years were included in this study. The only exclusion criteria was insufficient data on the medical records.

The patients were classified according to Montreal Classification for $\mathrm{CD}^{(16)}$, which establishes three parameters of classification: age of onset, behaviour of the disease, and location.

The following complications were analyzed: fistulae, abscesses, anastomotic dehiscence, and abdominal sepsis. Socio-demographic data (sex, ethnicity, age, schooling), clinical features (BMI, age at diagnosis, disease duration, family history, history of smoking, use of corticosteroids, immunomodulators or anti-TNF drugs within 8 weeks prior to surgery, Montreal classification of CD), and surgical characteristics (age at first surgery, time between diagnosis and first surgery, need for more than one surgery, number of surgeries, surgical indication, surgical time, technique and position of the anastomosis, presence of complications and their classification, and size of the removed specimen) were also analyzed.

Complications were classified according to the method proposed by Clavien-Dindo ${ }^{(17)}$ (grade I to V), that stratifies them according to the therapy that was necessary for their treatment, which makes this model ideal for retrospective studies, such as the present.

The variables were analyzed in a descriptive way, including their relative and absolute frequencies (for the categorical variables) and the calculation of the mean or median and the standard deviation (for the quantitative variables). The variables were then separated into clinical and surgical, and analyzed associatively using chi-square or Fisher's exact test (for categorical variables), and Student's t-tests or the Mann-Whitney (for the statistical variables), assuming a value of statistical significance of $P=0.05$. The program used for such analyzes was STATA $12.0^{(18)}$.

\section{RESULTS}

\section{Descriptive analysis}

A total of 44 surgical procedures were analyzed in 37 patients, $21(56.7 \%)$ female, $32(86.5 \%)$ white, and $18(49 \%)$ with complete secondary education. The mean age at diagnosis is 32.5 years (standard deviation $[\mathrm{SD}]=11.4)$; the mean age of the patients at the first surgery is 35.7 years $(\mathrm{SD}=10.9)$, and the median time between diagnosis and the first surgery is 1 year.

Only $8.1 \%$ of the patients had a family history of CD; $21.6 \%$ of the patients have a history of current or previous smoking; and $12(32.4 \%)$ required more than one surgery.

The highest incidence of $\mathrm{CD}(67.6 \%)$ occurred between 12 and 40 years of age (A2 from Montreal); the most common location $(75.7 \%)$ of the disease was ileocolonic (L3 of Montreal); and stricturing (B2) and penetrating (B3 Montreal) behaviors showed the same frequency $(48.65 \%)$. Complications occurred in 16 patients $(46.2 \%)$, and the most common was the presence of fistulas $(35.1 \%)$.

Of the total number of surgeries, $70.5 \%$ were elective; 6 surgeries $(13.7 \%)$ required blood transfusion; and the approach of all surgeries performed was through laparotomy. The mean duration of the surgeries was 181.1 minutes ( $\mathrm{SD}=43.9)$, and the median length of the removed specimen was $25 \mathrm{~cm}$, with a range of 8.5 to $99 \mathrm{~cm}$.

The rate of postoperative complications was 40.9\% (18 complicated surgeries, out of a total of 44). Half of these complica- tions (nine) occurred within 30 days of the surgical procedure. There were $15(34.1 \%)$ surgeries complicated by fistulas; $10(22.7 \%)$ surgeries complicated by abscesses; $5(11.3 \%)$ surgeries complicated by anastomotic dehiscence; and $2(4.5 \%)$ surgeries complicated by abdominal sepsis. Of the 18 complications occurred, $5(11.3 \%)$ were classified as IIIa; $11(25 \%)$ as IIIb; and $2(4.5 \%)$ as IVb, according to Clavien-Dindo ${ }^{(14)}$ as shown in TABLE 1.

TABLE 1. Incidence of complications.

\begin{tabular}{lcc}
\hline Variables & N & $\%$ \\
\hline Complications & 18 & 40.9 \\
Any complication & 15 & 34.1 \\
Fistula & 10 & 22.7 \\
Abscess & 05 & 11.3 \\
Anastomotic dehiscence & 02 & 4.5 \\
Abdominal sepsis & & \\
Clavien-Dindo ${ }^{13}$ classification & 05 & 11.3 \\
IIIa & 11 & 25.0 \\
IIIb & 02 & 4.5 \\
IVb & & \\
\hline
\end{tabular}

\section{Associative analysis}

Of the 37 studied patients, $12(32.4 \%)$ required more than one surgery. There was no significant association between the need for additional surgery and gender, ethnicity, schooling or smoking.

There was no significant difference between the need for additional surgery in the future and elective or emergency indication for the surgery; the use of corticosteroids, immunomodulators or biological up to 8 weeks before surgery; anastomotic features or extension of the specimen removed in the first operation. However, family history for $\operatorname{CD}(P=0.028)$ and duration of disease in years $(P=0.04)$ were significantly associated with the need for additional surgery, as shown in TABLE 2.

There was a significant difference $(P=0.013)$ in the clinical behavior of disease in the groups with and without general complications after surgery (including fistulas, abscesses, wound dehiscence and sepsis). The penetrating behavior (B3 of Montreal) was associated with a higher frequency of complications.

In addition, there was also a significant difference $(P=0.02)$ in the extension of the removed specimen in the surgeries with postoperative complications when compared to the extension of the specimen in the uncomplicated surgeries. Removal of specimens greater than $25 \mathrm{~cm}$ was associated with a higher rate of complications such as fistulae, abscesses, anastomotic dehiscence, and abdominal sepsis ( $P=0.019$, relative risk of 3.69), as shown in TABLE 3. None of the drugs (corticoids, immunomodulators and biologics) was associated with a higher occurrence of complications.

According to the classification of Clavien-Dindo ${ }^{(17)}$, the severity of the studied complications was not significantly influenced by the type of surgical indication, the use of drugs (corticoids, immunomodulators or biologics) up to 8 weeks prior to surgery, anastomosis technique or size of the removed specimen, as shown in TABLE 4. 
TABLE 2. Clinical characteristics of the patients according to the need for additional surgery after the first surgery.

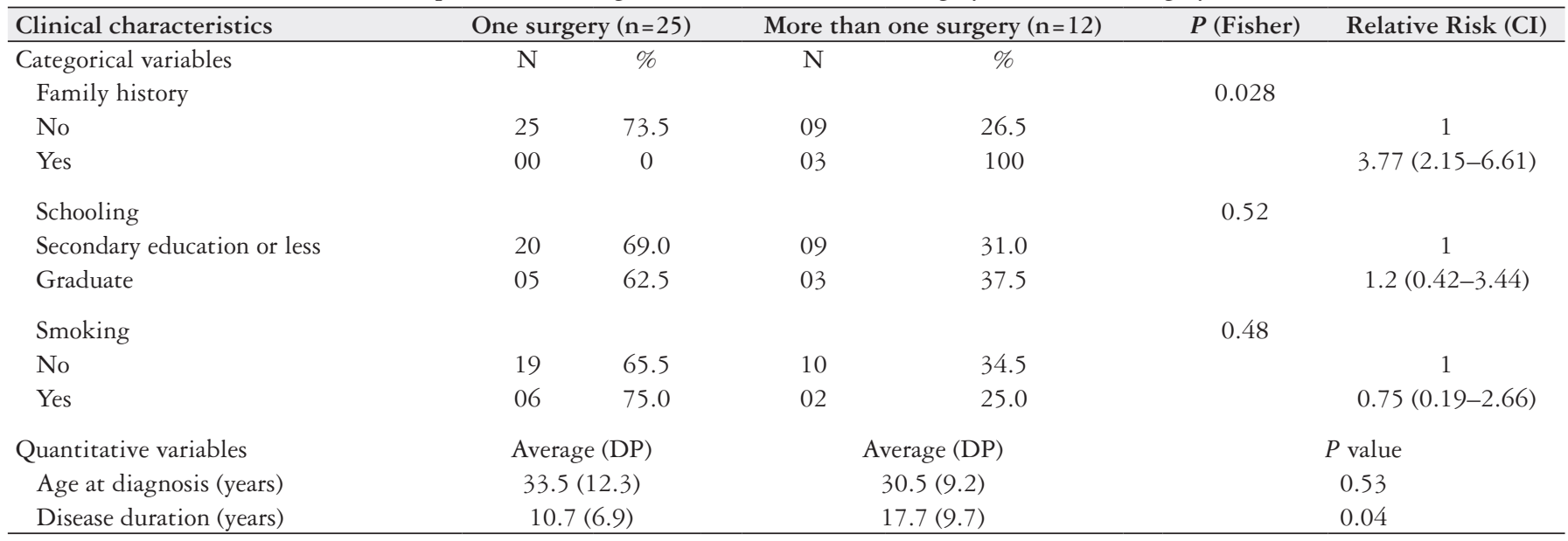

TABLE 3. Surgical characteristics according to the presence of postoperative complications.

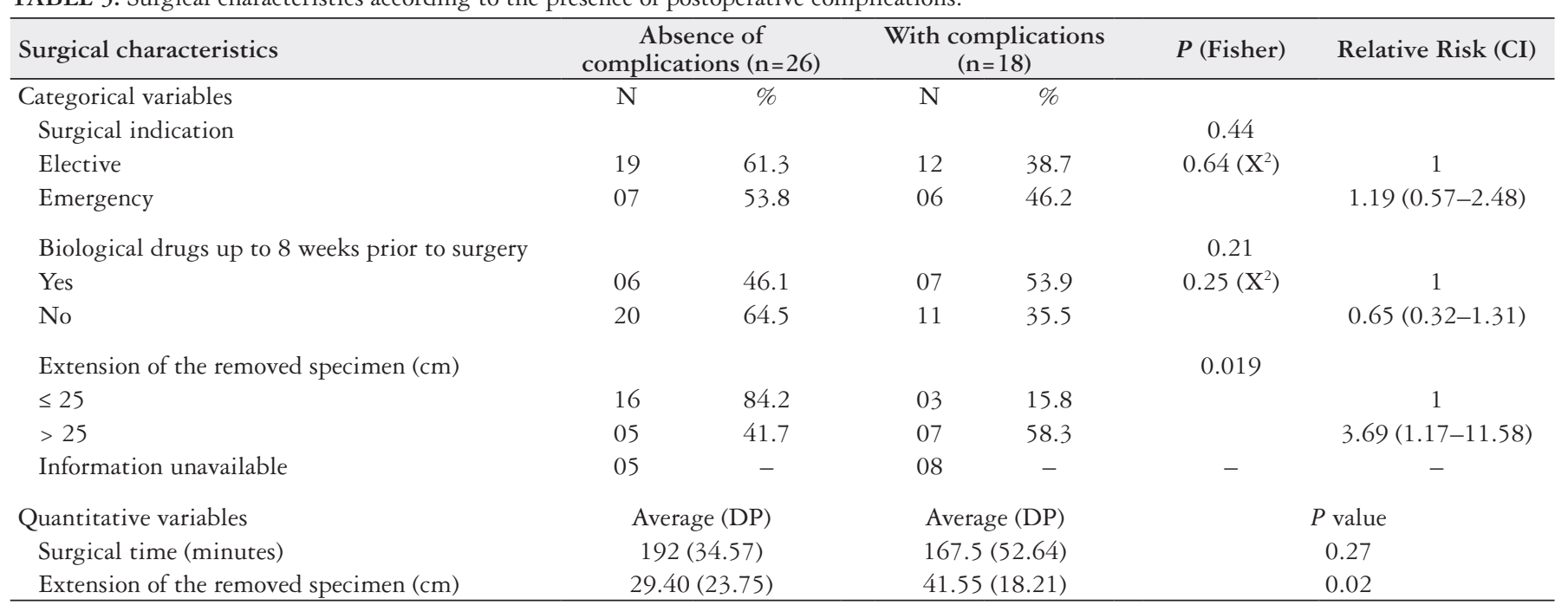

TABLE 4. Relation between surgical characteristics and postoperative complications, according to the therapy necessary to treat them ${ }^{(17)}$.

\begin{tabular}{|c|c|c|c|c|c|c|c|}
\hline \multirow{3}{*}{$\begin{array}{l}\text { Surgical characteristics } \\
\text { Categorical variables }\end{array}$} & \multicolumn{6}{|c|}{ Classification according to the model proposed by Clavien-Dindo ${ }^{14}$} & \multirow{3}{*}{$\begin{array}{c}P \\
\text { (Fisher) }\end{array}$} \\
\hline & \multicolumn{2}{|c|}{ IIIa $(n=05)$} & \multicolumn{2}{|c|}{ IIIb $(n=11)$} & \multicolumn{2}{|c|}{$\mathrm{IVb}(\mathrm{n}=02)$} & \\
\hline & $\mathrm{N}$ & $\%$ & $\mathrm{~N}$ & $\%$ & $\mathrm{~N}$ & $\%$ & \\
\hline Surgical indication & & & & & & & 1.00 \\
\hline Elective & 03 & 60.0 & 08 & 72.7 & 01 & 50.0 & \\
\hline Emergency & 02 & 40.0 & 03 & 27.3 & 01 & 50.0 & \\
\hline Biological drugs up to 8 weeks prior to surgery & & & & & & & 0.29 \\
\hline \multicolumn{8}{|l|}{ Anastomosis (technique) } \\
\hline Mechanical & 02 & 40.0 & 06 & 54.5 & 01 & 50.0 & 1.00 \\
\hline Manual & 02 & 40.0 & 03 & 27.3 & 00 & 00.0 & \\
\hline Information unavailable & 01 & 20.0 & 02 & 18.2 & 01 & 50.0 & \\
\hline
\end{tabular}


There was a significant difference between the group of patients with and without fistulas in the postoperative period regarding to the clinical behavior of the disease $(P=0.003)$. The penetrating behavior (B3 of Montreal) was associated with a higher frequency of fistulas. Thus, there is a tendency to maintain the penetrating behavior after surgery.

The time between diagnosis and the first surgery was also different between these two groups $(P=0.04)$, with the longest periods associated with the group with fistulas. There was no significant difference between gender, ethnicity, family history or smoking among these groups. There was no significant association between the use of corticosteroids, immunomodulators and biological agents up to 8 weeks prior to surgery and the presence of fistulas, nor between the characteristics of the anastomosis and the presence of fistulas.

The only significant association related to the presence of abscesses after surgery was the Body Mass Index (BMI) of the patients, with the highest BMIs being associated with the abscess group $(P=0.02)$. There was no significant association between the presence of abscesses and gender, ethnicity, family history, smoking, use of medications (corticoids, immunomodulators and biologics), or anastomotic features.

There were no significant associations between the variables studied and the presence of anastomotic dehiscence or abdominal sepsis.

\section{DISCUSSION}

The present study analyzed 44 surgical procedures in 37 highcomplexity patients in a reference hospital of the Midwest of São Paulo state. Its results show that treatment of CD remains challenging, especially when the disease has a penetrating behavior. The number of patients and the retrospective design of the study are limitations. However, despite this limitation, the study is important to analyze CD in the Midwestern Sao Paulo state, and its results corroborate with many other studies in the literature.

The gender distribution of the patients in this study is similar the one reported in the literature ${ }^{(19)}$. The ileocolonic location is the most common among patients undergoing conventional (open) surgery for $\mathrm{CD}$ in several studies found in the literature ${ }^{(13,20)}$. The highest incidence of $\mathrm{CD}$ between 12 and 40 years of age (A2 of Montreal) is also reported in the literature as the most common among patients requiring surgery ${ }^{(13)}$.

The literature reports ${ }^{(13)}$ a lower rate of postoperative complications in laparoscopic surgeries, especially in cases of mild to moderate non-fistulizing CD. However, it was not possible to study the difference between the surgical approaches, since all the surgeries performed in the present study had a conventional approach. The need for reoperation is also lower in laparoscopic approach surgeries, according to the literature ${ }^{(13)}$. Although it is available in our group, the hospital cost policy difficult the use of laparoscopy, especially at the time when the study was conducted. Recently in the hospital, an inflammatory bowel disease surgical team was assembled, and this team began to use the laparoscopic approach to CD patients, with only a few recent cases operated. New studies will be conducted to evaluate the results of this new approach in our group.

The rate of postoperative complications was $40.9 \%$ (18 complicated surgeries, out of 44), which is consistent with the rates reported in the literature ${ }^{(13,21,22)}$. The fact that the hospital in which the study was conducted is the only tertiary referal hospital for the entire midwest of the state of São Paulo, which comprehend more than 2 million people, may explain the relatively high value of complications. In this scenario, the patients that are referred to us usually have a more aggressive and severe disease, and they usually have been using medications for a long time, increasing the risk of postoperative complications.

Regarding the high rate of fistula, the authors believe that it occurred because the patients that are referred to our group usually have been treating CD for a long time, have a severe clinical state, many of them have chronic obstructive symptoms and malnutrition, and many of them were operated in an urgent scenario. Besides, at the time of this study, every gastrointestinal surgeon in our hospital operated on CD patients - including surgical residents; nowadays we have implanted an inflammatory bowel disease surgical team that comprises two expert surgeons. With this measure, the results seem to be subjectively improved over the last year. Another possible explanation is that the low number of patients included in this study had a negative influence on this analysis.

In a recent retrospective study ${ }^{(23)}$, published in 2015, both the ileocolonic location and the penetrating behavior of $\mathrm{CD}$ were associated with a greater surgical recurrence of the disease, resembling what was found in the present study, in which the latter were associated with a higher incidence of postoperative complications. The complexity of the treatment of penetrating-behavior $\mathrm{CD}$ was again highlighted in a recent systematic review ${ }^{(24)}$ and in a recent retrospective muticentric study ${ }^{(25)}$. All of that indicates that the penetrating behavior is an indication of severity and poor prognosis on $\mathrm{CD}$.

The use of corticosteroids, despite showing a clear benefit in the treatment of the acute phase of inflammatory bowel diseases, is associated with negative repercussions in the postoperative period by most authors, such as increasing the rate of postoperative complications ${ }^{(26-28)}$ and increasing postoperative mortality ${ }^{(29)}$. In the present study, however, no relation was observed between the presence of complications and corticosteroid therapy up to 8 weeks prior to surgery, probably because of the small sample. The authors believe that an increase in the patient number would confirm this relation.

There are controversies in the literature regarding the influence of biological therapy on the rate of postoperative complications. There are meta-analyzes showing that these drugs exert a protective effect against postoperative complications ${ }^{(30,31)}$, and there are others showing an increase in the rate of postoperative complications ${ }^{(21,32-35)}$ related to the use of these drugs. In the present study, there was no evidence that the biological drugs influence the rate of postoperative complications, resembling what was found in recent studies ${ }^{(22,25)}$.

The removal of a specimen greater than $25 \mathrm{~cm}$ was associated with both higher rates of general complications and higher incidence of postoperative fistulas. Thus, it seems that conservative resections regarding specimen extension are a way to reduce the rate of postoperative complications.

Another important alternative regarding the reduction of the rate of complications and the need for reoperation is the laparoscopic approach, which is not routinely practiced in our group in patients with $\mathrm{CD}$.

There are only a few papers in the international literature discussing this matter, especially in Latin America, and the results presented in this paper contribute to the current discussion regarding the perioperative complications of IBD, especially CD. 


\section{CONCLUSION}

Treatment of $\mathrm{CD}$, despite numerous advances, remains challenging, with high rates of postoperative complications. Family history, duration of disease, extension of the removed specimen, penetrating behavior and degree of nutrition are important risk factors for the presence of complications in the postoperative period.

Conservative resections of the segments affected by CD may be an important measure aimed at reducing the rate of postoperative complications.

\section{ACKNOWLEDGEMENTS}

The authors are grateful to the patients that participated in this study and to São Paulo Research Foundation (FAPESP), for the one-year scholarship granted to the researcher José Donizeti de Meira Júnior.

\section{Authors' contribution}

Saad Hossne R: idealizer and coordinator of the project and editor of the article. Sassaki LY: coordinator of the project and editor of the article. Baima JP: reviewer of the article. Meira Júnior JD, Campos LM: data collectors and text writers.

Saad Hossne R, Sassaki LY, Baima JP, Meira Júnior JD, Campos LM. Análise dos fatores de risco e complicações pós-operatórias em pacientes portadores de doença de Crohn. Arq Gastroenterol. 2018,55(3):252-7.

RESUMO - Contexto - O índice de complicações pós-operatórias é maior em pacientes com doença de Crohn do que em outras cirurgias abdominais decorrentes de outras afecções benignas. A prevenção e o manejo de tais complicações constituem importante fator no tratamento desses pacientes. Objetivo - Os objetivos deste trabalho são analisar a taxa de complicações pós-operatórias e os principais fatores de risco em pacientes portadores de doença de Crohn. Métodos - Estudo descritivo e retrospectivo, baseado na análise dos prontuários dos pacientes com doença de Crohn submetidos a ressecções ileais e/ou colônicas, analisando as principais complicações cirúrgicas e os principais fatores de risco relacionados as mesmas. Resultados - Foram analisados 44 procedimentos cirúrgicos em 37 pacientes. A maioria dos pacientes era do sexo feminino (56,7\%). Complicações pós-operatórias foram observadas em $18(40,9 \%)$ cirurgias. A duração da doença $(P=0,04)$, o comportamento penetrante $(P=0,013)$, o tempo entre o diagnóstico e a primeira cirurgia $(P=0,04)$, a desnutrição com baixo índice de massa corpórea (IMC), o tempo de duração da cirurgia $(P=0,016)$, e o tamanho do espécime retirado $(P=0,014)$ estiveram associados a maiores taxas de complicações. O uso de fármacos bloqueadores do fator de necrose tumoral até oito semanas antes da cirurgia não foi significativamente associado a maiores taxas de complicações ou a maior necessidade de reoperação. Conclusão - A taxa de complicações observadas neste trabalho é semelhante aos dados da literatura. A duração da doença, o comportamento penetrante, o tamanho do espécime retirado, o tempo de duração da cirurgia e o IMC são importantes fatores de risco para complicações peri-operatórias em doença de Crohn.

DESCRITORES - Prevenção secundária. Fatores de risco. Procedimentos cirúrgicos do sistema digestório. Complicações pós-operatórias. Doença inflamatórias intestinais.

\section{REFERENCES}

1. Xavier RJ, Podolsky DK. Unravelling the pathogenesis of inflammatory bowel disease. Nature. 2007;448:427-34.

2. Abraham C, Cho JH. Inflammatory bowel disease. N Engl J Med. 2009;361:2066-78.

3. Molodecky Na, Soon IS, Rabi DM, Ghali WA, Ferris M, Chernoff G, et al. Increasing incidence and prevalence of the inflammatory bowel diseases with time, based on systematic review. Gastroenterology. 2012;142:46.e42-54.e42; quiz e30.

4. Burisch J, Pedersen N, Čuković-Čavka S, Brinar M, Kaimakliotis I, Duricova $\mathrm{D}$, et al. East-West gradient in the incidence of inflammatory bowel disease in Europe - the ECCO-EpiCom inception cohort. Gut. 2014;63:588-97.

5. Kappelman MD, Moore KR, Allen JK, Cook SF. Recent trends in the prevalence of Crohn's disease and ulcerative colitis in a commercially insured US population. Dig Dis Sci. 2013;58:519-25.

6. Victoria CR, Sassaki LY, Nunes HRC. Incidence and prevalence rates of inflammatory bowel diseases, in midwestern of São Paulo State, Brazil. Arq Gastroenterol. 2009;46:20-5.

7. Souza MH, Troncon LE, Rodrigues CM, Viana CF, Onofre PH, Monteiro RA, et al. [Trends in the occurrence (1980-1999) and clinical features of Crohn's disease and ulcerative colitis in a university hospital in Southeastern Brazil]. [Article in Portuguese]. Arq Gastroenterol. 2002;39:98-105.

8. Gaburri PD, Chebli JM, de Castro LE, Ferreira JO, Lopes MH, Ribeiro AM, et al. [Epidemiology, clinical features and clinical course of Crohn's disease: a study of 60 cases]. [Article in Portuguese]. Arq Gastroenterol. 1998;35: 240-6.

9. Gardiner KR, Dasari BV. Operative management of small bowel Crohn's disease. Surg Clin North Am. 2007;87:587-610.

10. Syed A, Cross R, Flasar M. Preoperative use of anti-TNF therapy in Crohn's disease patients is associated with increased infectious and surgical complications. Am J Gastroenterol. 2013;108:583-93.
11. Yun L, Rubin DT, Ali T. Risk of post-operative complications associated with anti-TNF therapy in inflammatory bowel disease. World J Gastroenterol. 2012;18:197-204.

12. Kweku A, Fazio VW, Shen B, Church JM, Lashner B, Remzi F, et al. Use of Infliximab within 3 Months of Ileocolonic Resection is Associated with Adverse Postoperative Outcomes in Crohn's Patients. J Gastrointest Surg. 2008;12:1738-44.

13. Kotze PG, Abou-Rejaile VZ, Barcelos IF, Martins JF, Miranda EF, Rocha JG, Kotze LMS. Complications after intestinal resection in Crohn's disease: laparoscopic versus conventional approach. J Coloproctol (Rio J). 2013;33:139-44.

14. Narula N, Charleton D, Marshall JK. Meta-analysis: peri-operative anti-TNFo treatment and post-operative complications in patients with inflammatory bowel disease. Aliment Pharmacol Ther. 2013;37:1057-64.

15. Kotze PG, Saab MP, Saab B, da Silva Kotze LM, Olandoski M, Pinheiro LV, et al. Tumor Necrosis Factor Alpha Inhibitors Did Not Influence Postoperative Morbidity After Elective Surgical Resections in Crohn's Disease. Dig Dis Sci. 2017;62:456-64.

16. Silverberg MS, Satsangi J, Ahmad T, Arnott ID, Bernstein CN, Brant SR, et al. Toward an integrated clinical, molecular and serological classification of inflammatory bowel disease: Report of a Working Party of the 2005 Montreal World Congress of Gastroenterology. Can J Gastroenterol. 2005;19:5A-36A.

17. Dindo D, Demartines N, Clavien PA. Classification of surgical complications: a new proposal with evaluation in a cohort of 6336 patients and results of a survey. Ann Surg. 2004;240:205-13

18. Stata Corporation, 2011. Stata Statistical Software. Release 12.0. Stata Corporation, College Station, TX.

19. Bobanga ID, Bai S, Swanson MA, Champagne BJ, Reynolds HJ, Delaney CP, et al Factors influencing disease recurrence after ileocolic resection in adult and pediatric onset Crohn's disease. Am J Surg. 2014;208:591-6.

20. Cayci M, Bostanci EB, Turhan N, Karaman K, Dalgic T, Ozer I, et al. The analysis of clinico-pathologic characteristics in patients who underwent surgery due to stricturing and non-perineal fistulizing forms of Crohn's disease: A retrospective cohort study. Int J Surg. 2015;15:49-54. 
21. Billioud V, Ford AC, Tedesco ED, Colombel JF, Roblin X, Peyrin-Biroulet L. Preoperative use of anti-TNF therapy and postoperative complications in inflammatory bowel diseases: A meta-analysis. Journal of Crohn's and Colitis. 2013;7:853-67.

22. Kotze PG, Magro DO, Martinez CAR. Adalimumab and postoperative complications of electiveintestinal resections in Crohn's disease: a propensity score case-matched study. Colorectal Dis. 2017;20:211-8.

23. Bechara Cde S, Lacerda Filho A, Ferrari Mde L, Andrade DA, Luz MM, da Silva RG. Montreal classification of patient operated for Crohn's disease and identification of surgical recurrence predictors. Rev Col Bras Cir. 2015;42:97-105.

24. Schlussel AT, Steele SR, Alavi K. Current challenges in the surgical management of Crohn's disease: a systematic review. The American Journal of Surgery. 2016;212:345-51.

25. Yamamoto T, Spinelli A, Suzuki Y, Saad-Hossne R, Teixeira FV, de Albuquerque IC, et al. Risk factors for complications after ileocolonic resection for Crohn's disease with a major focus on the impact of preoperative immunosuppressive and biologic therapy: A retrospective international multicentre study. United European Gastroenterol J. 2016;4:784-93.

26. Nguyen GC, Elnahas A, Jackson TD. The impact of preoperative steroid use on short-term outcomes followingsurgery for inflammatory bowel disease. J Crohn's Colitis. 2014;8:1661-7.

27. Lichtenstein GR, Feagan BG, Cohen RD, Salzberg BA, Diamond RH, Price $\mathrm{S}$, et al. Serious infection and mortality in patientswith Crohn's disease: more than 5 years of follow-up in the TREATTM registry. Am J Gastroenterol 2012;107:1409-22.
28. D'Haens G, Colombel JF, Hommes DW, Panes J, Rutgeerts PJ, Ekbom A, et al. Corticosteroids pose an increased risk for serious infection: an interim safety analysis of the ENCORE Registry. Gastroenterology. 2008:134-40.

29. Ropelato RV, Kotze PG, Junior IF, Dadan DD, Miranda EF. Postoperative mortality in inflammatory bowel disease patients. J Coloproctol (Rio J). 2017;37:116-22.

30. Zhao Y, Ma T, Chen YF, He XY, Ren LH, Chen J, et al. Biologics for the prevention of postoperative Crohn's disease recurrence: A systematic review and meta-analysis. Clin Res Hepatol Gastroenterol. 2015;39:637-49.

31. Rosenfeld G, Qian H, Bressler B. The risks of post-operative complications following pre-operative infliximab therapy for Crohn's disease in patients undergoing abdominal surgery: A systematic review and meta-analysis. J Crohns Colitis. 2013;7:868-77.

32. Narula N, Charleton D, Marshall JK. Meta-analysis: Peri-operative Anti-TNF $\alpha$ Treatment and Post-operative Complications in Patients With Inflammatory Bowel Disease. Aliment Pharmacol Ther. 2013;37:1057-64.

33. Lau C, Dubinsky M, Melmed G, Vasiliauskas E, Berel D, McGovern D, et al. The Impact of Preoperative Serum Anti-TNF $\alpha$ Therapy Levels on Early Postoperative Outcomes in Inflammatory Bowel Disease Surgery. Ann Surg. 2015;261:487-96.

34. Yang Z, Hong L, Wu Q, Wu KC, Fan DM. Preoperative infliximab use and postoperative complications in Crohn's disease: A systematic review and meta-analysis. Int J Surg.2014;12:224-30

35. Jouvin I, Lefevre JH, Creavin B, Pitel S, Chafai N, Tiret E, et al. Postoperative Morbidity Risks Following Ileocolic Resection for Crohn's Disease Treated With Anti-TNF Alpha Therapy: A Retrospective Study of 360 Patients. Inflamm Bowel Dis. 2018;24:422-32. 